\title{
Facilitation: A Novel Way to Improve Students' Well-being
}

Adriansen, Hanne Kirstine Olesen; Madsen, Lene Møller

Published in:

Innovative Higher Education

DOI:

10.1007/s10755-012-9241-0

Publication date:

2013

Document version

Early version, also known as pre-print

Citation for published version (APA):

Adriansen, H. K. O., \& Madsen, L. M. (2013). Facilitation: A Novel Way to Improve Students' Well-being. Innovative Higher Education, 38(4), 295-308. https://doi.org/10.1007/s10755-012-9241-0 


\title{
Facilitation: A Novel Way to Improve Students' Well-being
}

\author{
Hanne Kirstine Adriansen • Lene Møller Madsen
}

Published online: 19 October 2012

(C) Springer Science+Business Media New York 2012

\begin{abstract}
In this article we analyze a project that used facilitation techniques, which are known from training in industry, to improve the study environment at a public research university in Denmark. In 2009, the project was initiated in one graduate program; and it has subsequently been modified and institutionalized. The project did not change the teaching format, but introduced facilitated study-groups using peer learning. It was successful in increasing students' well-being. While peer learning and study groups are well-known in higher education, facilitation is a different and novel tool. We argue that facilitation makes study groups more inclusive, and they provide the potential for deep learning by structuring the learning situation.
\end{abstract}

Keywords Facilitation techniques · Study-groups · Peer-learning · Students' well-being

Increasing student enrollment and decreasing resources for teaching is a common reality for many universities and colleges throughout the world. The consequences of a psychologically poor study environment can be severe and lead to poor student well-being, as seen in a report from a Danish University concerning students' experience of their study environment (AU 2008a, 2008b). In this article, we analyze and discuss a novel approach to the well-known problem: the use of facilitation to improve the study environment and hence students' well-being.

Hanne Kirstine Adriansen is Associate Professor in the Department of Education at Aarhus University in Denmark. She received her Ph.D. from the University of Copenhagen. Her special interests include teaching innovation and creativity in higher education, facilitation of knowledge processes, and student retention. She can be contacted at hkoa@dpu.dk

Lene Møller Madsen is Associated Professor in the Department of Science Education at the University of Copenhagen in Denmark. She received her Ph.D. from the University of Copenhagen. Her special interests include university students' first year experiences, learning geography, students' interests, and retention within science. She can be contacted at lmmadsen@ind.ku.dk

H. K. Adriansen $(\bowtie)$

Department of Education, Aarhus University, Tuborgvej 164, 2400 Copenhagen NV, Denmark e-mail: hkoa@dpu.dk

L. M. Madsen

Department of Science Education, University of Copenhagen, Oester Voldgade 3, 1350 Copenhagen K, Denmark e-mail: 1mmadsen@ind.ku.dk 
In 2008, Aarhus University published a report on the University's study environment. According to this report, a study environment is made up of psychological, physical and aesthetical elements. However, the report only concerned the psychological study environment and equated a good study environment with well-being (AU 2008a). The report showed that the approximately 33,000 students at Aarhus University were generally satisfied with their studies. The School of Education with approximately 4000 students, however, stood out with the poorest study environment and the least satisfied students among the eight main academic areas at Aarhus University. We do not know the reasons for the low scores, but we conjecture they might be attributed in part to high teacher/student ratios, which means that large lecture classes dominate. As the majority of the students are mature students who have a social life outside campus, there is little incentive and possibility for interaction. All together this means that they have many hours of individual studying. With the report in mind, a research group on "facilitation of knowledge processes" within the School of Education decided to initiate a project to address the issue of the poor study environment by using facilitation techniques. While the project team's evaluation of the facilitation project in the School stated it was a success and the subsequent institutionalization suggests the same, we wanted to understand the reasons for success. We also wanted to analyze if and how facilitation adds to the well-known benefits of peer-led study-groups. Consequently, the aim of our examination reported in this article was threefold: we wanted to analyze the project in order to understand the success, we wanted to address the novelty of facilitation, and we wanted to provide guidelines for others considering using facilitation to improve students' well-being.

\section{Methodology}

Facilitation was the theoretical underpinning of the project. While this concept and approach is known from training in industry and public organizations (Hughes 1999; 2002), little is known about the theoretical foundations of facilitation in general and the learning rationale in particular. Therefore, we begin with an outline of facilitation as the theoretical framework for the project. We then explain the novelty of facilitation in higher education by describing the techniques involved in facilitating peer learning in study groups and provide details of the similarities and differences between facilitation and related approaches.

In order to understand why the project was a success and how facilitation can be used to tackle a sense of low student well-being, we sought to analyze the project and its institutionalization. We wanted to probe more deeply and understand the success in relation to two parameters - study environment and study groups. Our focus was on the use of facilitation techniques and the outcome for the students. The original project went through a number of changes as it was institutionalized, and these are described in order to be able to provide recommendations. The project was supported by and financed by the Dean of the School. Approval for the project and for using this project for research purposes was obtained prior to its beginning.

It should be noted that one of the authors was a member of the project group. Being an insider is not unusual within educational research (Sikes and Potts 2008). According to Adriansen and Madsen (2009), there are both advantages and disadvantages when conducting research on the inside. Being an insider in relation to one's interviewees has the advantage of having a shared history and a close knowledge of the context. The disadvantages concern power relations and presupposed shared understanding. We tackled the disadvantages by being aware of the insider role from the outset and addressed the questions of positionality and power relations both during interviews and during the analysis. In 
writing this article we found it beneficial to have both an insider and an outsider perspective. Further the insider position gave access to the original data material from the project.

\section{Theoretical Framework: Facilitation}

To facilitate means to assist, to aid, or to make easy. A facilitator is someone who helps a group to accomplish what it wants. Hence, the facilitator does not decide the goal of the group's work; the facilitator merely helps the group achieve its goal. Within the formalized concept of facilitation there is a distinction to be made between content and process: "Facilitation is about process - how you do something - rather than content - what you do" (Hunter 2007, p. 19). The facilitator is responsible for designing and running the process leading the group towards a result. Consequently, a facilitator is an expert on process, not on content, and has a number of tools and techniques for designing processes (e.g., Justice and Jamieson 2006); and these are outlined in a script, which is the specialty term used in facilitation. Some sentences are written down, and time is noted rather precisely.

Facilitation builds on fields such as adult education, group dynamics, and process consultation; and it is used for purposes such as improving meetings (Doyle and Straus 1982), handling complex group processes (Ghais 2005), and promoting facilitative leadership (Bens 2006). There is a certain educational rationale and perception of learning inherent in the methods and thinking underlying facilitation practices. However, most often these are not discussed explicitly. John Heron's The complete facilitator's handbook (2000) is an exception as he was very explicit about the thoughts on learning which constitute the basis of his facilitation practice. In Heron's view, learning has four components that complement and support each other. He labeled these components experiential, imaginal, conceptual, and practical (2000, p. 3). Experiential learning is the foundation: people learn from experience. Therefore it is important that students have the possibility to connect their experiences to the theoretical knowledge introduced by the teacher. Imaginal learning leads to representational knowing as it concerns our intuitive comprehension of a whole. Conceptual learning is the intellectual, verbal level. Here learning is expressed in statements and propositions, thus related to propositional knowing. Practical learning is how-to-do learning and entails learning a skill. Another important tenet of Heron's educational rationale is co-operation with peers. According to Heron, students can only become self-directed learners when they participate in relationship with other self-directing students. Thus, group-based learning and peer feedback on practice and experience become important tools for facilitating learning.

Facilitation has primarily been used for groups of adults. Hence, the underlying educational rationale concerns, but may not be limited to, the fields of higher, adult, and continuing education. It rests on the premise that student learning is self-directed, based on the individual's exercise of intelligence, choice, and interest. The primary responsibility for learning thereby rests with the self-directing learner. Consequently, a facilitator can enable self-directed learning (Heron 2000).

\section{Facilitating Peer Learning in Study Groups}

Numerous studies have shown the benefits of peer learning and study groups as a means to increase academic as well as social outcomes and belonging (e.g. Micari et al. 2008; Tinto 1997). In this context, we relied on Boud's understanding of peer learning as mutual learning (Boud 2001). Likewise, a number of researchers have also pointed to the importance of 
using questions for enhancing students' learning (e.g. Crosling et al. 2009). Therefore the question for use in higher education is how facilitation adds something new and different.

When using facilitation in study groups, the groups should consist of about 6-14 persons (preferably 8-10) in order for the facilitation to be effective. Even though this is a relatively large group, the process should not be mistaken for what occurs in traditional discussion sections. Teaching per se does not take place; graduate student teaching assistants are not used; the facilitator does not deliver content, rather process. The facilitator is a student from the same cohort, consequently a real peer who has expertise in the process of facilitation. Thus, facilitated study groups are an alternative to unstructured study groups.

We find the consequences of taking process seriously to be the main difference between facilitated study groups and peer-led study groups. What does it imply to take process seriously? We explain this in five segments so as to illustrate how facilitated study groups are different from other study-groups:

- The use of techniques

- The use of a script

- The use of a facilitator

- Agreeing on a meeting culture and

- The use of experiential questions

Although these elements are to some extent interdependent, we will discuss them separately:

By using different techniques such as silent reflection and splitting the group up into buzzing pairs, the facilitator makes room for different ways of learning. Silent reflection is a good technique for introverts so as to allow the members of the group time to think before they answer. This ensures a more active participation. Likewise buzzing in pairs allows extroverts to articulate their thoughts before participating in the wider group. Splitting into smaller groups means there is more time for each person to speak, which means there is more time to develop verbal academic skills.

The use of a script means that the facilitator knows how to structure the time used for a study group meeting (Table 1 shows two examples of scripts). There is a plan and a purpose for the meeting, and small talk is minimized because everybody knows that there is an agenda. Questions guiding the students' reading should be sent out beforehand.

The facilitator is the person in charge of the script and has a broader role as a host of the meeting. This means that the other participants can focus solely on the content as the facilitator takes care of the process. This implies that the facilitator can focus the discussion and has the legitimacy to interrupt talkative types.

Agreeing on a meeting culture should be done during the first meeting so as to ensure that there are certain ground rules accepted by all, and the group need spend no further time on this issue. For instance, the group should agree if cell phones will be turned off and should discuss what to do with latecomers.

The use of experiential questions is uncommon in higher education while academic questions are conventional: "What is the main argument in the article?", "What are the differences and similarities between the two concepts?" Experiential questions are used in order to increase the students' subjective relevancy of the text allowing them to connect their personal and professional experiences to the content of the texts. Examples of experiential questions are as follow: "What was the most important point in the article for you and why?" "How does the concept relate to your experiences as a 
Table 1 Examples of two scripts directed at different types of students (introvert and extrovert), questions (experiential and academic), and number of articles to be discussed

\begin{tabular}{|c|c|c|c|}
\hline \multicolumn{2}{|c|}{ Script 1 one article, experiential, 'introvert' } & \multicolumn{2}{|c|}{ Script 2 two articles, academic, 'extrovert' } \\
\hline $5 \mathrm{~min}$ & $\begin{array}{l}\text { introduction by the facilitator to the } \\
\text { purpose of the meeting }\end{array}$ & $5 \mathrm{~min}$ & $\begin{array}{l}\text { introduction by the facilitator to } \\
\text { the purpose of the meeting }\end{array}$ \\
\hline $5 \mathrm{~min}$ & $\begin{array}{l}\text { silent reflection on a question given } \\
\text { by the facilitator }\end{array}$ & $10 \mathrm{~min}$ & $\begin{array}{l}\text { discussion in triads "What is the } \\
\text { main argument in the first article?" }\end{array}$ \\
\hline $20 \mathrm{~min}$ & $\begin{array}{l}\text { discussion in pairs "What inspired } \\
\text { you in the article?", "Explain how the } \\
\text { article is relevant for you in regard } \\
\text { to your work life" }\end{array}$ & $10 \mathrm{~min}$ & $\begin{array}{l}\text { discussion in triads "What is the main } \\
\text { argument in the second article?" }\end{array}$ \\
\hline $20 \mathrm{~min}$ & $\begin{array}{l}\text { 'round robin' sharing the thoughts } \\
\text { on the questions }\end{array}$ & $15 \mathrm{~min}$ & $\begin{array}{l}\text { discussion in triads "What are the } \\
\text { similarities and differences } \\
\text { between the two articles?" }\end{array}$ \\
\hline $5 \mathrm{~min}$ & $\begin{array}{l}\text { planning next meeting, choosing } \\
\text { text and questions }\end{array}$ & $15 \mathrm{~min}$ & $\begin{array}{l}\text { new triads "Share the discussion } \\
\text { from the previous triads" }\end{array}$ \\
\hline $5 \mathrm{~min}$ & $\begin{array}{l}\text { reflection on individual learning points, } \\
\text { 'take-aways' }\end{array}$ & $5 \mathrm{~min}$ & $\begin{array}{l}\text { planning next meeting, choosing } \\
\text { text and questions }\end{array}$ \\
\hline
\end{tabular}

practitioner?" Experiential questions may not be directly related to process; rather they should be understood as a content issue. Nevertheless, the experiential questions serve a process purpose because those students who do not feel very competent answering academic questions can contribute and participate in the study-group.

\section{The Study}

The report from Aarhus University (AU), as mentioned earlier, was based on a survey sent to all students; and it revealed a good study environment at Aarhus University in general (AU 2008a). However, for the School of Education the results were not satisfactory (AU 2008b). The postgraduate degree-program in educational psychology was a case in point as it was among the lowest scoring, (see Table 2). Therefore this program, which admits some 250 students every year, was the target of the project on facilitation. The project took place during the spring term of 2009 and involved the remaining 222 students from the cohort admitted in the autumn of 2008. The project consisted of three components: facilitated study groups, social gatherings with facilitated activities, and an academic identity event. These three elements were chosen in order to deal with the problems, which the faculty felt could be addressed using facilitation techniques but did not require changes to teaching formats and methods.

\section{The Study Context}

For historical reasons, the School of Education offers predominantly postgraduate/master programs, and bachelor students were first admitted in 2010. The majority of the classes were large lectures, and there was little opportunity for interacting with faculty members. There were only a few hours of classes every week, which meant that the majority of studying was individual reading most often done at home. The degree program in question attracted primarily people with a professional background such as primary school and kindergarten teachers, nurses, and physiotherapists. Note that in Denmark these are not 
Table 2 Study environment at Aarhus University (AU), School of Education (SoE) and the degree-program in educational psychology (EP)

\begin{tabular}{|c|c|c|c|c|c|}
\hline & Percentage agreeing to the statement & AU 2007 & SoE 2007 & EP 2007 & EP 2009 \\
\hline 1 & I feel a sense of belonging to the degree program & 55 & 24 & 21 & 60 \\
\hline 2 & $\begin{array}{l}\text { The likelihood of social interaction with } \\
\text { my fellow students is high }\end{array}$ & 72 & 32 & 29 & 74 \\
\hline 3 & $\begin{array}{l}\text { The program has contributed to my sense of } \\
\text { belonging to an academic community }\end{array}$ & 74 & 54 & 48 & 70 \\
\hline 4 & $\begin{array}{l}\text { Generally, my well-being is high when } \\
\text { participating in the program }\end{array}$ & 83 & 69 & 67 & 84 \\
\hline 5 & In general, the other students are forthcoming & 82 & 78 & 80 & 91 \\
\hline 6 & I feel lonely - on a daily basis on campus & 9 & 16 & 19 & 8 \\
\hline 7 & I feel lonely - on a daily basis off campus & 6 & 5 & 5 & 8 \\
\hline 8 & $\begin{array}{l}\text { My interest in the program's academic field has } \\
\text { grown since I began studying }\end{array}$ & 85 & 88 & 90 & 90 \\
\hline 9 & $\begin{array}{l}\text { My degree program has contributed to clarifying } \\
\text { what kind of job I would like when I finish my studies }\end{array}$ & 43 & 33 & 32 & 32 \\
\hline
\end{tabular}

AU 2007: Aarhus University, $n=8469$, response rate $28.5 \%$ (AU 2008a)

SoE 2007: School of Education, $n=630$, response rate $19.7 \%$ (AU 2008b)

EP 2007: Educational Psychology, $n=192$, response rate $22.1 \%$ (AU 2008b)

EP 2009: Educational Psychology - post intervention, $n=156$, response rate $70.3 \%$ (from questionnaire)

university degrees. The majority of the students had a professional career before embarking on their postgraduate studies. Some had established a family, and they were on average 10 years older than traditional Danish university students. Most often, the students commuted, and some had several hours of transport a day. Due to their age and the fact that going to university is only one in a number of their everyday obligations, these students may be less inclined to engage socially compared with undergraduates working on their first degree. Also, making friends can be difficult at a commuter institution when people only meet once or twice a week during large lectures.

The Project

The project, which was entitled "Improving the Study Environment through Facilitation," was based on Heron's educational rationale (2000). It began with a call for potential student facilitators among the cohort that was the target group. The call explained the project and made it clear that there was no payment or extra credit to be earned by acting as a facilitator. However, facilitation is a valued competence in both private and public organizations; and the students were offered a workshop which would normally be quite expensive. By acting as facilitators for their peers they would gain facilitation competencies. Out of the 19 students who volunteered, 2 fell ill and could not participate in the workshop. Through a two-day residential workshop experience, 17 students learned how to act as facilitators for a study group. In addition to explanatory lectures on facilitation, the workshop involved practical training, e.g. how to keep a discussion focused and to interrupt very talkative types, how to make a script and use different techniques to make sure everybody had been heard, and how to use questions to support learning. Especially important were the use of experiential questions. Through such questions the students engage their experiences, which is important according to Heron (2000). 
By using this kind of question, students can help each other relate practical problems and theoretical concepts and thereby promote the transfer of knowledge (Billing 2007). Moreover, experiential questions can assist students in creating transfer between their professional experiences and theories of educational psychology.

After the workshop, each student facilitator was assigned a group of 10-14 students. During their first meeting, the group agreed on a meeting culture, which meant they discussed how to deal with cell phones, latecomers, the role of the facilitator (participate in content discussions or not), and other issues of relevance for making the group work smoothly. Each group met for one hour before every lecture (in total 15 times) and discussed the texts for the lecture. The facilitator guided the group through the process, making sure that discussions were focused and that everybody had a say. The 60 minutes were planned and structured beforehand through a script which included different techniques. Table 1 shows examples of two scripts emphasizing different types of students and learning.

By using different techniques, questions. and processes, everybody had a chance to participate without anyone dominating the group discussions. By listening to the experiences of others, they came to notice differences in views and experiences.

The use of study groups is not new; it is the use of facilitation which is new. The students had ordinary study groups during their first terms, and faculty members frequently encourage students to form study groups. The main difference between ordinary study groups and facilitated study groups is that the facilitated groups make use of a facilitator who is responsible for structuring the time instead of having 60 minutes of free discussion. In ordinary study groups students are self-organizing which usually means there is no organization of structure to the meetings and nobody to ensure discussions stay focused.

The above descriptions of the aspects of facilitated study groups can be linked to a deeper learning approach as described by Biggs and Tang (2011). Encouraging the students to relate their professional experiences to theoretical content, working with the content by discussing concepts and relating others' perceptions to one's own understanding, and relating the text to the content of the lectures all contribute to a deep learning approach.

The other two components of the project were facilitated social gatherings and academic identity events. The three social gatherings lasted for about 4 hours each and consisted of both facilitated socializing (organized games and activities with an academic twist) and informal socializing. Facilitated socializing allowed people to get to know somebody within a few hours even though they did not know anybody from the outset. The social gathering was facilitated by the project team with the help from some of the student facilitators. The academic identity event took about 3 hours and concerned possible career paths for the students. As the majority of students were professionals with a well-established identity, enrolling at university could be related to a loss of professional identity; especially because educational psychology is not a well-known academic degree in Denmark.

\section{Evaluation Methods}

The evaluation methods consisted of a questionnaire on students' well-being, interviews with facilitators, and observation of study groups. The questionnaire included nine questions from the Aarhus University report in order to compare the results of the project with the original report. Further, questions on participation, experiences, and outcomes of the facilitated study groups, the social gatherings, and the academic identity event were included. The questionnaire had both closed and open-ended questions and was completed during the last class of the semester. Everybody present in the room answered the questionnaire (responding being voluntary), which yielded a response rate of $70 \%(\mathrm{~N}=222)$. This is an 
efficient way to get a high response rate, but it is costly as the answers subsequently had to be registered electronically. We held qualitative interviews and focus groups interviews with 15 of the 17 study-group facilitators concerning their role as facilitators, the content of the group meetings, and outcomes for them personally. We observed three study-group meetings, noting how the meeting was structured by the facilitator, the type of questions used, and the participants' contributions.

\section{Findings}

The questionnaire showed that $69 \%$ of the students participated in the study groups "always" or "often"; $40 \%$ participated in the first social gathering (the questionnaire was handed out before the other two social gatherings) and $44 \%$ in the academic identity event. The study groups met at least 15 times over a period of 3-4 months. Hence, a great deal of time and energy were devoted to the facilitated study groups. Consequently, we argue that our findings can be attributed to the facilitated study groups. When analyzing the data, we first looked at the study groups and then at the study environment.

\section{Facilitated Study Groups}

According to the questionnaire, $69 \%$ of the students participated in the study groups "always" or "often;" and $21 \%$ participated "sometimes". While $83 \%$ stated that the social outcome was good, $80 \%$ indicated that the academic outcome was good. It is worth noting that $80 \%$ stated the outcome was good even though only two thirds were there "often." The interviews showed that the groups became a way to make the School of Education a more familiar place for the students. Because the groups served both as a forum for discussing the curriculum and as a way of getting to know others, they served two needs: social and academic interaction. One of the facilitators admitted that before the project she would "sneak in and out of class" and then study in solitude off campus. Now she "feels at home" at campus and is more pleased with studying there. Another facilitator commented from a discussion in her group: "They say it has become a social network that the study has changed. There are more people they can turn to. You talk while queuing. You feel you belong. You smile when you enter. You know people's names" (Sue). On the outcome of the facilitated study groups, typical answers were: "I found out that I was not the only person who didn't understanding the text", "I got a social network", and "Discussing the text gave a much deeper understanding". Please note that the interviews were conducted in Danish and that we have chosen verbatim translations rather than linguistically correct ones throughout the paper.

During observations we could see that the use of questions was important to the work in the study groups; the same was reported in the interviews. Using both academic and experiential questions in the facilitation process required students to rethink what they knew and to become personally involved in deciding how they knew it. Thus, facilitation can induce students to take ownership of the learning process: "Because it wasn't all 'Who knows most about Bourdieu?' we dared contribute. And by anchoring it in one's practice meant that people felt that they were capable and in that way people dared discuss more" (Sue). The interviewees also pointed out that the facilitated study groups functioned as a place to connect the academic content to the students' life in a wider perspective. This effect can probably be ascribed to the use of experiential questions. The students noted the benefits of encountering the diversity of views and experiences of group members. Finally, some 
students also said that the questions helped them structure the way they were reading at home:

I think it is really cool in terms of knowledge, to get to apply some of the concepts in practice. And to have a focus on "Why is it that I study this?". Because at times at the module 1 I read without reflecting and then - after this facilitation stuff - you read in a different way. You think "How can I use his text? Or what interests me in this text?". That's one of the contributions [of facilitated study groups], I find. (Kathrin)

One student reflected on the difference between these groups and conventional study groups. In the latter, there were two members who were "gradually left behind. This experience I've never had in the facilitated group". She explained that this probably was due both to the facilitation, which meant that everybody was heard, and to the experiential questions, which meant that everybody had something to say. Another student framed it this way:

The benefit of being facilitated is that [the discussion] is managed in a manner which means that it doesn't end up in "coffee talk". It is somehow delimited... the purpose as I see it - is both social and academic. And really it is about making those two things merge. (Mary)

We believe that the interviews and observations illustrate how that facilitated study groups improved interaction and engagement among the students and thereby improved the study environment.

\section{Study Environment}

The outcome of the project in terms of improving the study environment was examined by comparing the answers from the questionnaire with answers from the Aarhus Universityreport (see Table 2). Before the project, educational psychology had low scores on many variables compared to the rest of the School of Education. Likewise, the School of Education had low scores compared to the other main academic areas at Aarhus University. The project led to a remarkable improvement in the well-being of students in the educational psychology program. It should be noted that the Aarhus University-survey (leading to the AU-report) had been sent to all students in educational psychology, while the project only addressed students in their second term in 2009. The background data on the respondents of the survey are similar to the background data of the students involved in the project. Therefore, we find it valid to make these comparisons; we did refrain, however, from testing for significance as the data do not allow this.

As Table 2 illustrates (column 3, EP 2007 to column 4, EP 2009), most remarkable is the increase in the "sense of belonging to the degree program," which tripled. Another remarkable result is the rise in "a high likelihood of social interaction with fellow students," which more than doubled. There has been an increase of almost $50 \%$ in the number of students who feel that "the program has contributed to my sense of belonging to an academic community" and likewise in "my well-being is high when participating in the program". The score on "the other students are forthcoming" also increased even though it was high already. The number of lonely students was more than halved. This result is especially noteworthy when compared to the number of lonely students off campus, which has increased. We do not know the cause of this increase, but we do not assume it is related to the project.

Two elements, however, have not changed at all. One of them, "my interest in the program's academic field has grown since I began studying" was already high (90\%) and higher than for the School of Education in general and for Aarhus University. Therefore a 
further increase is unlikely. However, the other one, "my degree program has contributed to clarifying what kind of job I would like when I finish my studies," was fairly low (32\%). For the School of Education in general, it was $33 \%$ and at Aarhus University in general $43 \%$. Hence, a high score is not expected. It is noticeable, however, that there has been no improvement.

When analyzing the scores in educational psychology before the project (column EP 2007), an interesting story emerges. The students were very interested in the program's academic field (no. 8) from the outset and found that the other students were forthcoming (no. 5). They did not, however, feel a sense of belonging, either to the degree program (no 1) or to the academic community (no. 3). It was striking that the likelihood of social interaction was considered to be low (no. 2). Hence, it is not enough that the other students are forthcoming when there is no or only little interaction with them. Therefore, we consider interaction to be a key to the success observed here. Apparently, the students do not create sufficient interaction themselves; it has to be facilitated, preferably in relation to the academic content. We suggest that the introduction of facilitated study groups has increased student interaction, leading directly to a remarkable improvement in this element (column 4, EP 2009, no. 2). Consequently, we interpret the increase in the sense of belonging to be an important derived outcome of the increased interaction. Hence, by increasing the interaction, the sense of belonging is also increased and the feeling of loneliness reduced. Naturally, these elements also have a positive influence on the overall sense of well-being. However, it is more difficult to affect ideas about future job opportunities (column 4, EP 2009, no. 9). The academic identity event was intended to change this; but, as the results show, this event had little effect. Apparently, the facilitated study groups did not affect this particular aspect either.

Consequently, the findings from the questionnaire confirm the findings from the interviews and observations that facilitation did improve the well-being and the psychological study environment, which was the purpose of the project. Before we address how facilitation contributes novelty to well-known approaches such as peer learning and study groups, we will explain how the project was institutionalized.

\section{Institutionalization of the Project}

The outcome of the project was very positive, yet it was also quite costly. While it only involved the original faculty to a limited extent, the project members spent many hours on it. Therefore a less expensive approach had to be developed before the project could become institutionalized.

In the fall of 2009, we tried a new and smaller version. The academic identity events were dropped as these had been difficult to organize and apparently had little impact. The instructions for facilitated social events were handed over to the students, who were given the responsibility for their conduct. Hence, study groups were the only thing left. Instead of training one facilitator for each study group, all students in the cohort were offered a 2-day workshop in facilitation. This version of the project was less expensive because there were fewer teaching hours and fewer economic resources devoted to the project. The workshop, for instance, was nonresidential on the campus whereas the first one had been residential and held at a conference venue. In the first iteration the student facilitators had been closely monitored by faculty members whereas for the second iteration we offered the training to the whole cohort without further assistance. One-third of the cohort participated in the workshop. These students then took turns facilitating their groups. The second iteration if the project also led to improvements in the study environment although not as significantly as the first one when measured on the 
variables mentioned in the report from Aarhus University (see Table 3, third column (EP 2010). An evaluation of the second iteration can be seen in Adriansen et al. 2010).

In 2011 Aarhus University conducted a new survey of the study environment (AU 2011), which was sent to all students enrolled at the University. It shows the effects of the project (see Table 3, last column, EP 2011). However, one should keep in mind that some of the respondents may belong to cohorts that have not been part of the project. Therefore the results from the 2011 survey are likely to be lower than those expected when the project is fully implemented.

In fall 2010 the project was institutionalized in two of the School of Education's postgraduate degree programs and tested in the bachelor program. This final version of the project addressed the issues experienced in the two previous versions. The training in facilitation was reduced to half a day in groups of 40-50 students. It was integrated as part of the curriculum and labeled a course instead of an extra-curricular workshop. However, the combination of teaching and exercises was maintained. The study groups were reduced to 810 people, which was enough to split up the group for discussion in pairs and yet few enough that the students felt committed to the study group.

\section{Discussion}

In this article, we have argued that facilitation and thereby taking process seriously has been important for the project's success in improving students' sense of well-being. The facilitation of the study groups led to positive outcomes, which in turn lead to increased attendance in the groups. By sharing personal experiences, the students also came to know each other better, which likely contributed to the improvement in the study environment.

Based on our assessment of the project, we developed the following recommendations, which we offer to the wider academic community.

- It is important to integrate the training in facilitation into the ordinary curriculum instead of making it an extra-curricular activity. By integrating it, it is evident that facilitation is important for all students

- The training should be for all students, not only for a special group of facilitators. It is easier to facilitate people who understand facilitation, and the students can take turns facilitating instead of one person having the sole responsibility. This makes the study groups more robust in case the facilitator falls ill or drops out

- Having a facilitator who acts as host is important as this gives others the opportunity to engage fully in the content and leaves the responsibility for time keeping and group processes to the facilitator

- An optimal group size is 8-10 students. This is enough for splitting the group into smaller groups for buzzing pairs, yet not too many for people to lose the sense of group responsibility

- The use of a script including different techniques is an important way to ensure inclusion of all in discussions

- Experiential questions are a good supplement to academic questions because they allow students to engage with their personal experiences and to link from academia to worklife

Does following these recommendations mean that facilitated study groups will be useful everywhere? Unfortunately, using facilitated study groups is not a panacea. As mentioned in the first part of the article, the project was an attempt to improve the study environment in 


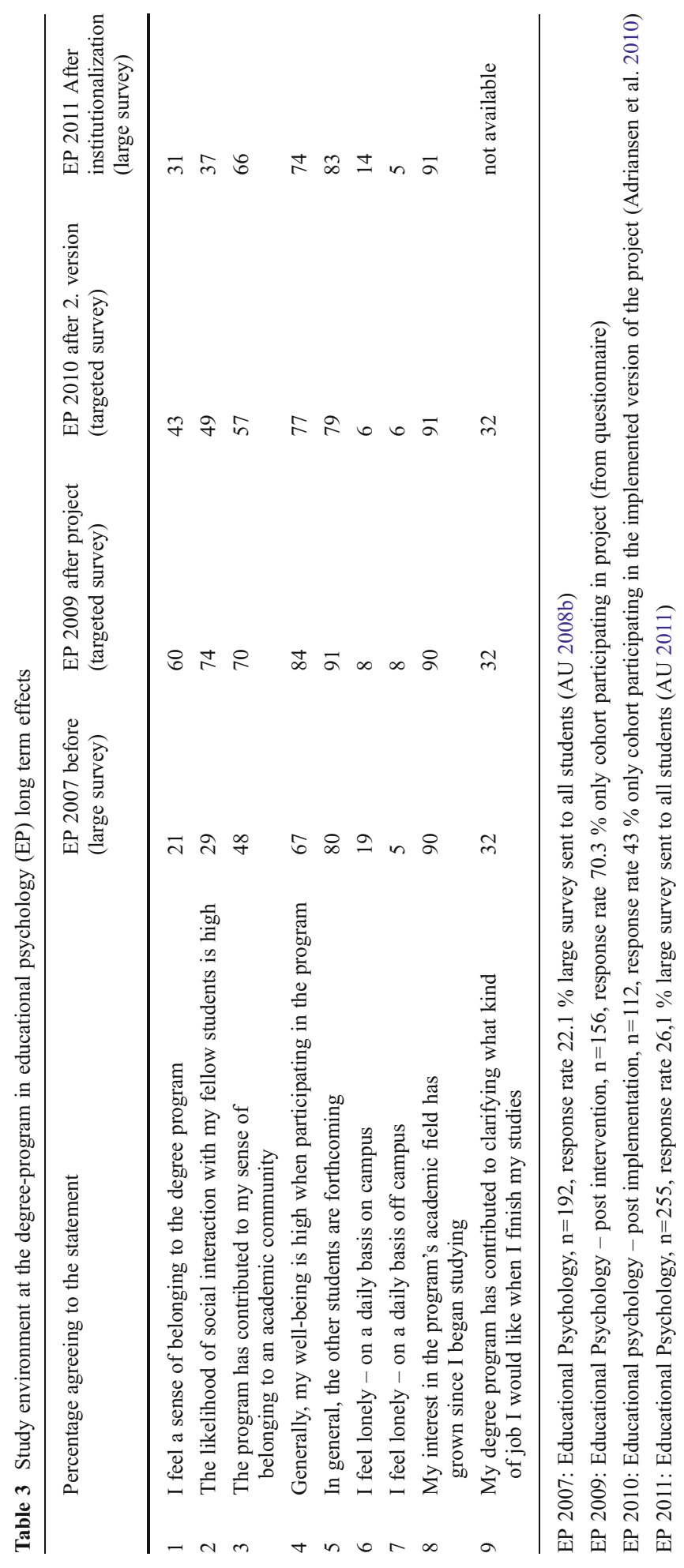


our School of Education. We argue that facilitated study groups can contribute to resolving some of the common problems with mature students in programs similar to ours.

In Denmark and most of Scandinavia, all universities are commuter universities with offcampus accommodations. Similar conditions are found in many European countries as well as in Australia and New Zealand. In these settings, facilitation may be a relevant tool for enhancing both learning and social interaction among students. However, we do not know yet whether facilitated study groups will be equally useful in residential colleges. Hence, while we find that peer learning and study groups are important tools in higher education, the tools need to be adjusted to the type of students and also to the type of problem to be resolved.

\section{Conclusion}

The point of departure for the project was to use facilitation for improving the study environment. The project succeeded in that respect. Prior to the project, the students were very interested in the academic field and found that other students were forthcoming. However, they did not feel a sense of belonging either to the degree program or to the academic community; and the likelihood of social interaction was low. We consider interaction to be key to the success of the project, and we conclude that the introduction of facilitated study groups has increased the interaction among the students. The increase in the sense of belonging and a reduction in loneliness is an important derived outcome of increased interaction. Naturally, these elements also have a positive influence on the study environment in general.

Peer-led study groups are well-established in higher education. Yet post-graduate, professional programs with mature students may call for different approaches to tackle the problem of high teacher/student ratios and little interaction between students. We have argued that by taking process seriously, by using a facilitator and a script with different techniques and experiential questions, the benefits of peer-led study groups can be taken a step further. The facilitative techniques make peer-led study groups more inclusive, and they provide the potential for deep learning by structuring the learning situation.

\section{References}

Adriansen, H. K., \& Madsen, L. M. (2009). Studying the making of geographical knowledge: The implications of insider interviews. Norsk Geografisk Tidsskrift - Norwegian Journal of Geography, 63(3), 145153.

Adriansen, H. K., Ravn, I., Tange, N. (2010). Faciliterede studiegrupper for nye studerende: Evaluering af et initiativ på DPUs kandidatuddannelse i Padagogisk Psykologi i efteråret 2009. Working Paper, DPU. Retrieved August 23, 2012 from tinyurl.com/fac-stud-nye

AU (2008a). Studiemiljø 2007, rapport 1: Aarhus Universitet - hovedresultater og nøgletal. Studieudvalget, Aarhus Universitet. Retrieved August 23, 2012 from http://www.au.dk/fileadmin/www.au.dk/uddannelse/ kvalitetsarbejde/statistik_og_analyse/stustudiemil_2007/hovedrapport.pdf

AU (2008b). Studiemiljø 2007, rapport 7: Resultater ōg nøgletal, Danmarks Padagogiske Universitetsskole, Aarhus Universitet. Studieudvalget, Aarhus Universitet. Retrieved August 23, 2012, from http:// www.au.dk/fileadmin/www.au.dk/uddannelse/kvalitetsarbejde/statistik_og_analyse/studiemiljoe 2007/ dpu.pdf

AU (2011). Studiemiljø 2011, undersøgelse af studiemiljøet ved Aarhus Universitet. Rapport nr. 5/Arts. Studieudvalget, Aarhus Universitet. Retrieved August 23, 2012, from http:/www.e-pages.dk/aarhusuniversitet/234/ 
Bens, I. (2006). Facilitating to lead! Leadership strategies for a networked world. San Francisco, CA: Jossey-Bass. Biggs, J., \& Tang, C. (2011). Teaching for quality learning at university (4th ed.). Philadelphia, PA: Open University Press.

Billing, D. (2007). Teaching for transfer of core/key skills in higher education: Cognitive skills. Higher Education, 53, 483-516.

Boud, D. (2001). Introduction: Making the move to peer learning. In D. Boud, R. Cohen, \& J. Sampson (Eds.), Peer learning in higher education: Learning from \& with each other (pp. 1-19). London, England: Kogan Page.

Crosling, G., Heagney, M., \& Thomas, L. (2009). Improving student retention in higher education: Improving teaching and learning. Australian Universities Review, 51(2), 9-18.

Doyle, M., \& Straus, D. (1982). How to make meetings work. New York, NY: Jove Books.

Ghais, S. (2005). Extreme facilitation: Guiding groups through controversy and complexity. San Francisco, CA: Jossey-Bass.

Heron, J. (2000). The complete facilitator's handbook. London, England: Kogan Page.

Hughes, C. (1999). Facilitation in context: Challenging some basic principles. Studies in Continuing Education, 21(1), 21-43.

Hughes, C. (2002). Issues in supervisory facilitation. Studies in Continuing Education, 24(1), 57-71.

Hunter, D. (2007). The art of facilitation. New York, NY: Wiley.

Justice, T., \& Jamieson, D. W. (2006). The facilitator's fieldbook. New York, NY: AMACOM.

Micari, M., Streitwieser, B., \& Light, G. (2008). Undergraduates leading undergraduates: Peer facilitation in a science workshop program. Innovative Higher Education, 30, 269-288.

Sikes, P., \& Potts, P. (Eds.). (2008). Researching education from the inside: Investigations from within. Oxon, England: Routledge.

Tinto, V. (1997). Classrooms as communities: Exploring the educational character of student persistence. Journal of Higher Education, 68, 599-623. 